\title{
Influence of degree of deformation in rolling on anneal hardening effect of a cast copper alloy
}

\author{
SVETLANA NESTOROVIC*, DESIMIR MARKOVIC and LJUBICA IVANIC \\ Technical Faculty Bor, University of Belgrade, Belgrade, Yugoslavia
}

MS received 15 May 2003

\begin{abstract}
This paper reports results of investigations carried out on a cast copper alloy containing 8 at.\% Al. The alloy, and pure copper for the sake of comparison, were subjected to cold rolling with a final reduction of 30,50 or $70 \%$.

The cold rolled copper and copper alloy samples were isochronally and isothermally annealed up to the recrystallization temperature. The hardness, strength and electrical conductivity were measured and $\mathrm{X}$-ray and DSC analyses performed.

Anneal hardening effect was observed in the alloy in the temperature range $180-300^{\circ} \mathrm{C}$, followed by an increase in the electrical conductivity. The amount of strengthening increases with increasing degree of prior cold work. The $\mathrm{X}$-ray analysis shows a change in the lattice parameter during annealing when anneal hardening effect was observed. The DSC analysis shows the exothermic character of this effect.
\end{abstract}

Keywords. Degree of deformation; anneal hardening; cast copper alloy.

\section{Introduction}

The strength properties of cold-worked substitutional solid solutions increased upon annealing up to the recrystallization temperature in several $\mathrm{Cu}$ based alloy systems. This strengthening effect is termed anneal hardening and is mainly applied to copper alloys when producing spring materials for electro-mechanical devices. Three general trends can be noted which characterize the phenomenon in all alloy systems. The amount of strengthening, which accompanies ageing, increases with increasing degree of prior cold work; the strengthening increases with increasing substitutional solute concentration; the strengthening due to ageing is a decreasing function of the plastic strain at which the strength is measured (Bader et al 1976; Vitek and Warlimont 1979).

The mechanism responsible for this hardening effect is investigated in several copper based alloys after cold rolling and annealing at $150-300^{\circ} \mathrm{C}$. The effect has been investigated mainly in cast copper base alloys and some observations have been interpreted as indicating that atomic ordering is primarily responsible for the hardening effect (Zehtebauer 1976). On the other hand, in a detailed investigation of anneal hardening in $\mathrm{Cu}-\mathrm{Al}$ alloys (Bader et al 1976), it was concluded that solute segregation to dislocations is the predominant hardening mechanism. However, the mechanism responsible for this hardening effect is not fully understood (Vitek and Warlimont 1979).

\footnotetext{
*Author for correspondence
}

This anneal strengthening effect is also observed in several sintered copper based alloys (Nestorovic et al 1997, 2002; Nestorovic and Markovic 1999, 2001).

\section{Experimental}

A cast copper alloy containing $8 \% \mathrm{Al}$ is selected for the present study. For comparison, parallel investigation has been carried out on specimens made from cast pure copper.

Copper and copper alloy weighing $\sim 2 \mathrm{~kg}$, were melted in a furnace and cast in copper molds with dimensions $80 \times 80 \times 30 \mathrm{~mm}$. The cast alloys were homogenized at $850^{\circ} \mathrm{C}$ for $24 \mathrm{~h}$. Samples with dimension $80 \times 30 \times 7 \mathrm{~mm}$ were cut from the homogenized material. Cold rolling was carried out on these samples with intermediate anneals at $500^{\circ} \mathrm{C}$ for $1 \mathrm{~h}$, a heat treatment of $500^{\circ} \mathrm{C}$ for $2 \mathrm{~h}$, followed by an ice-water quench. After that the copper and copper alloy were subjected to cold rolling with different final reduction of 30,50 and $70 \%$.

The cold rolled copper and copper alloy samples were isochronally and isothermally annealed up to recrystallization temperature, during which the values of hardness, strength and electrical conductivity were measured. Xray analysis was also performed.

\section{Results and discussion}

\subsection{Cold rolled cast samples}

The hardness of the samples during cold rolling increases with deformation due to strain hardening (figure 1). 
Higher hardness values were obtained for alloy due to solid solution hardening. Maximum value of hardness for copper is $126 \mathrm{HV}$ and for alloy, $207 \mathrm{HV}$ (deformation degree, $70 \%$ ).

Figure 2 shows the changes of electrical conductivity during cold rolling. It can be seen that the electrical conductivity for pure copper is higher than in the alloy. Also figure 2 shows that the electrical conductivity of the alloy slowly decreases with the deformation degree. However, it is known that the increase in cold working results in a decrease in electrical conductivity.

\subsection{Annealed cold rolled cast samples}

Figure 3 shows the dependence of hardness on annealing temperature for the copper and copper alloy samples with deformation degree-30, 50,70\%. It can be seen that the recrystallization temperature for copper for all applied deformation degrees is above $200^{\circ} \mathrm{C}$, but for the alloy, it is above $350^{\circ} \mathrm{C}$ for all deformation degrees; i.e. the alloying element $\mathrm{Al}$ cause an increase in the recrystallization temperature of pure copper.

Figure 3 shows that in the temperature range of 180$300^{\circ} \mathrm{C}$, for the alloy, the hardness value increases at all deformations $(30,50,70 \%)$. At $240^{\circ} \mathrm{C}$ the hardness values increase by about $9 \mathrm{HV}$ for deformation degree of $30 \%$, by $19 \mathrm{HV}$ for deformation degree of $50 \%$ and by $30 \mathrm{HV}$ for deformation degree of $70 \%$. The hardness values increase remarkably for $70 \%$ deformation in the alloy. This can be explained by the fact that the amount of strengthening effect i.e. anneal hardening effect increases with increasing degree of prior cold work (Nestorovic et al 1997; Nestorovic and Markovic 1999, 2001).

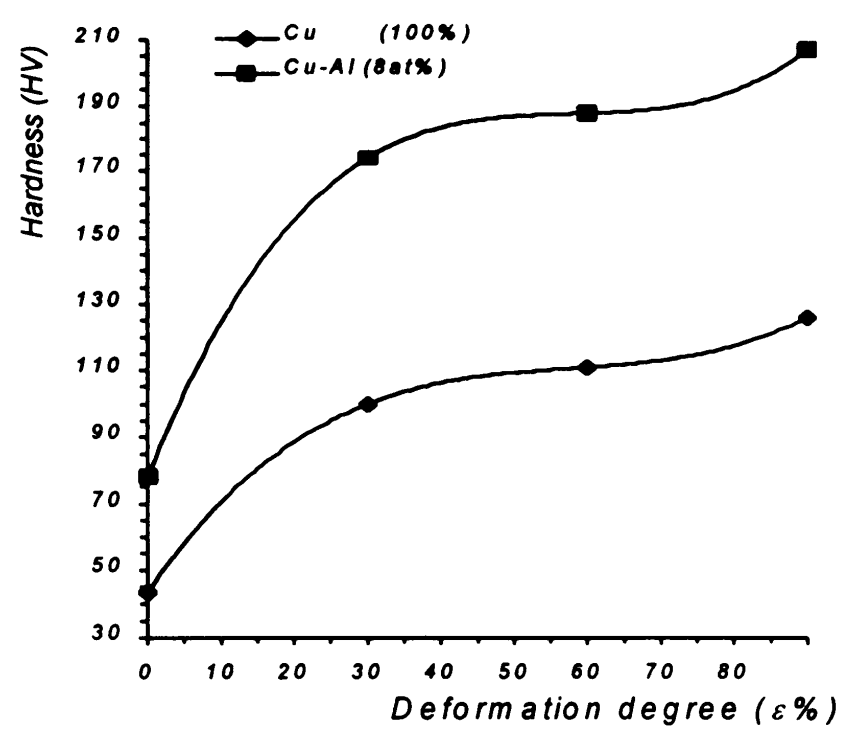

Figure 1. Dependence of hardness of cold rolled samples on deformation degree.
This effect has been investigated mainly in the cast copper-base alloys containing $\mathrm{Al}, \mathrm{Ni}, \mathrm{Au}, \mathrm{Ga}, \mathrm{Pd}, \mathrm{Rh}$ and $\mathrm{Zn}$. The results would tend to support the hypothesis that solute segregation to dislocation, analogous to the formation of Cottrell atmospheres in interstitial solid solutions, is primarily responsible for anneal hardening phenomenon (Vitek and Warlimont 1979).

During annealing the samples after cold rolling, the electrical conductivity of copper slowly increases with annealing temperature due to recovery and recrystalliza-

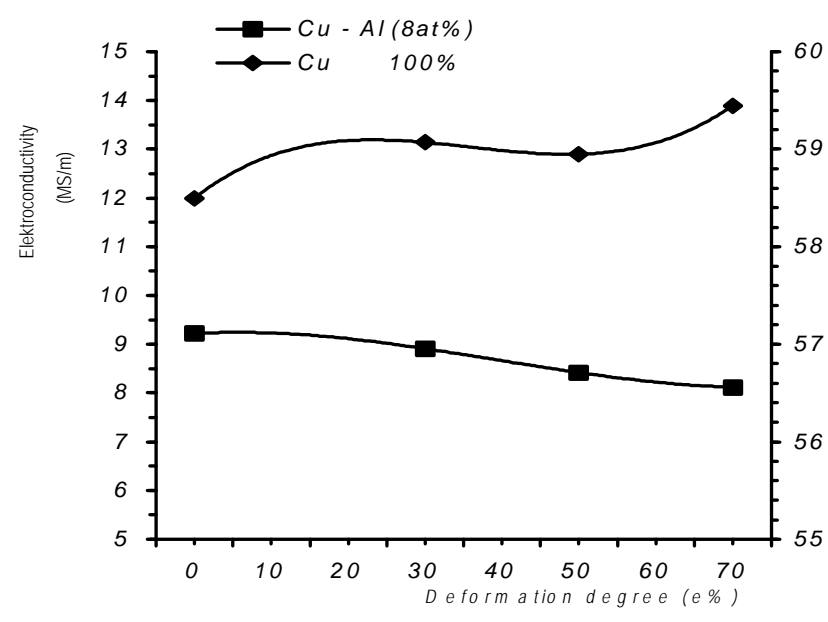

Figure 2. Dependence of electrical conductivity of cold rolled samples on deformation degree.

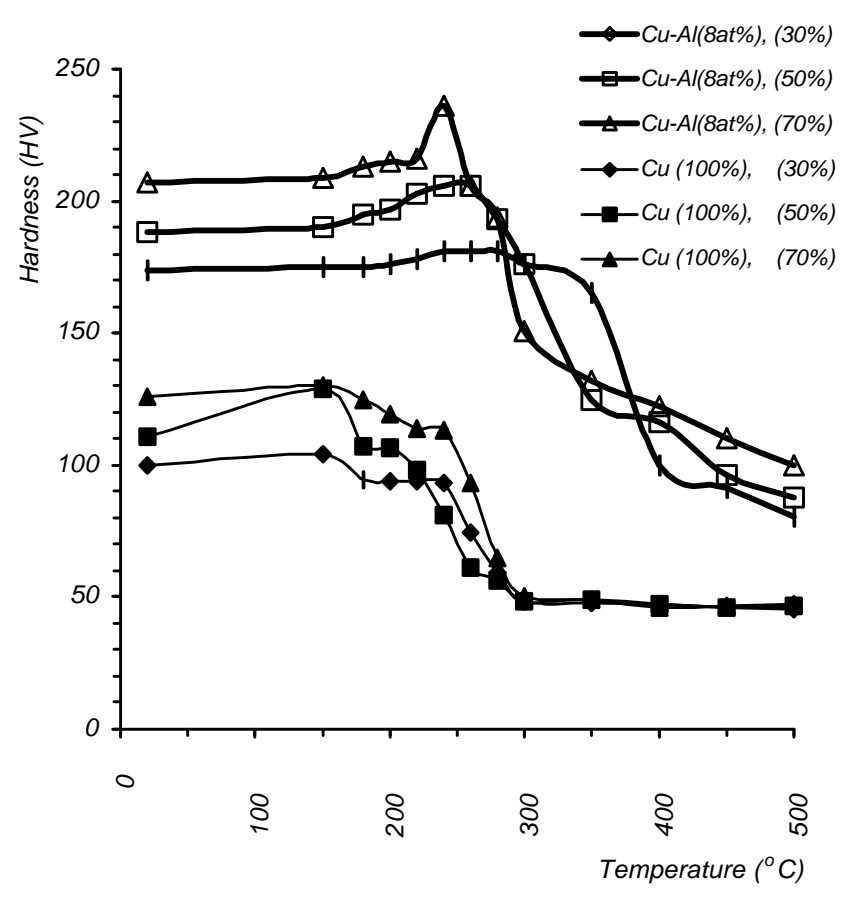

Figure 3. Hardness of cold-rolled samples of copper and copper alloy with annealing temperature. 
tion. The electrical conductivity of the alloy increases above $220^{\circ} \mathrm{C}$, due to the anneal hardening effect. Bader et al (1976) obtained similar results by electrical resistivity measurements.

Figure 5 shows the change in hardness with annealing time at $240^{\circ} \mathrm{C}$ for $70 \%$ deformation. It can be seen that the hardness increases for 30,60, 120, $150 \mathrm{~min}$, due to anneal hardening effect and after that decreases slowly with annealing time. After $5 \mathrm{~h}$ the hardness values are somewhat higher than for cold rolled state. It can be explained by the fact that anneal hardening effect has

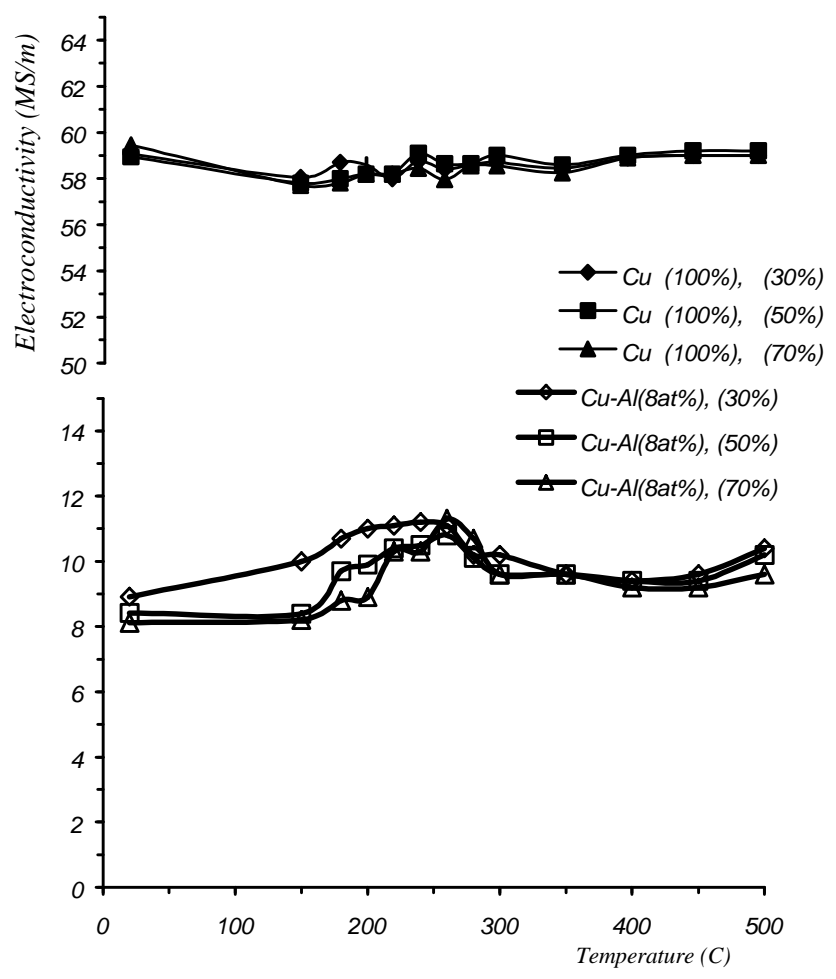

Figure 4. Electrical conductivity of cold-rolled samples of copper and copper alloy with annealing temperature.

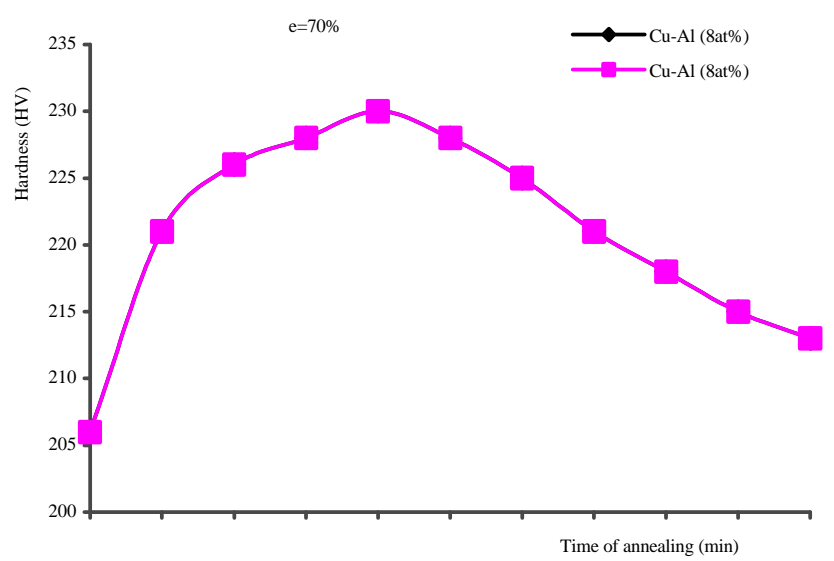

Figure 5. Hardness of cold-rolled samples as a function of time of annealing at $240^{\circ} \mathrm{C}$. influence on recrystallization temperature. After $120 \mathrm{~min}$ of annealing the maximum hardness values increase due to anneal hardening effect by about $30 \mathrm{HV}$. After $300 \mathrm{~min}$ of annealing, recrystallization still does not seem to have occurred, because the value of hardness is higher than for cold rolled state.

Figure 6 shows the change of electrical conductivity up to an annealing time of $300 \mathrm{~min}$ at $240^{\circ} \mathrm{C}$, for the alloy. It can be seen that electrical conductivity increases for the first $30 \mathrm{~min}$ due to anneal hardening effect and after that, it only slowly increases.

Finally, some property changes other than hardening response during annealing may be considered in support of solute segregation to dislocations. In the previous investigation of anneal hardening of a $\mathrm{CuAl}$ alloy (Bader et al 1976), it was shown that the major decrease in electrical resistivity during annealing cannot be accounted for by short range ordering. It was concluded that segregation to dislocations is the only consistent interpretation for the major portion of the change in resistivity.

Figure 7 shows the exothermic effect of deformed specimens of $\mathrm{Cu}-\mathrm{Al}$ upon heating, as revealed by DSC analysis. The exothermic heat effect is found in the temperature range $210-300^{\circ} \mathrm{C}$ where the anneal hardening effect is also observed.

The lattice parameter changes in the alloy during annealing, have also led to the conclusion that solute clustering at dislocations should be one of the major causes of the observed changes.

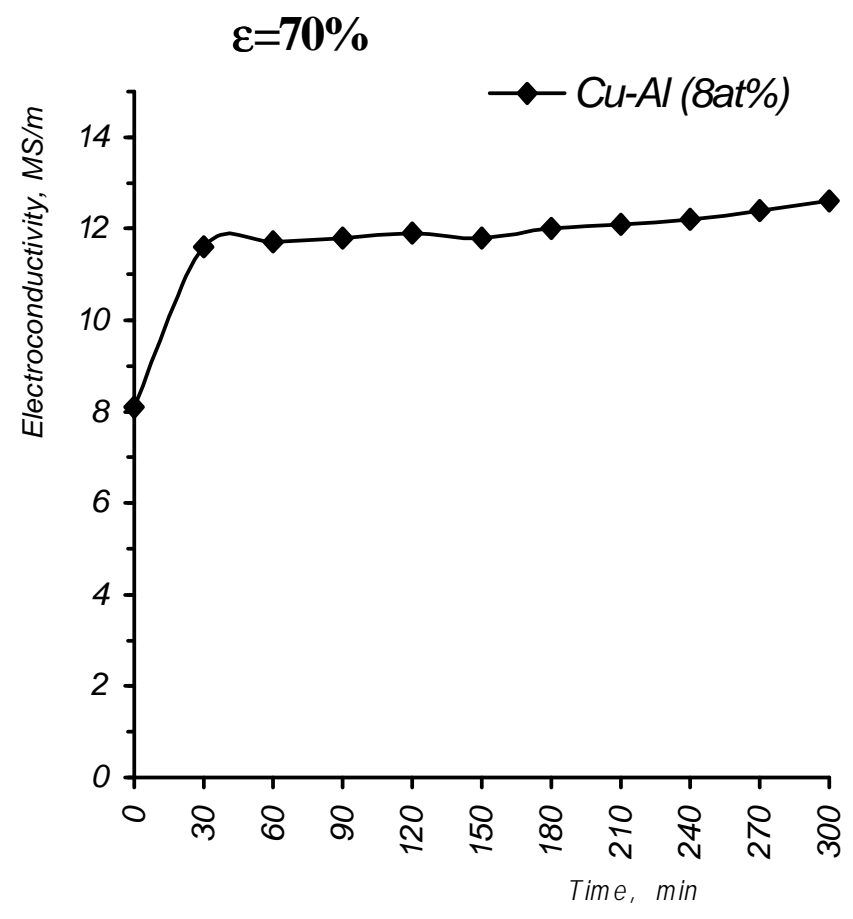

Figure 6. Electrical conductivity of cold-rolled samples of copper alloy as a function of time of annealing at $240^{\circ} \mathrm{C}$. 


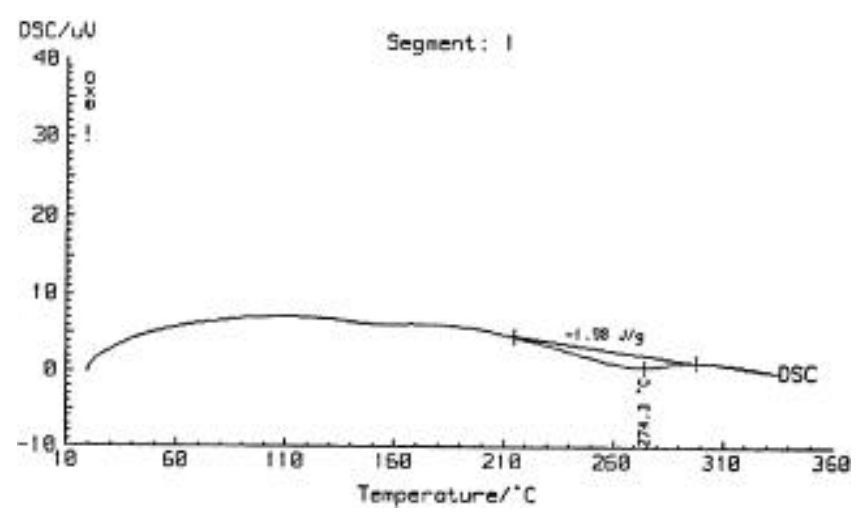

Figure 7. $\mathrm{DSC}$ for cold rolled samples of $\mathrm{Cu}-\mathrm{Al}$ alloy deformed to $70 \%$.

The anneal hardening effect is well known in $\mathrm{Cu}$ based solid solution alloys. This is due to the fact that these alloys are widely used as spring contact materials where strength in the elastic/plastic limit is of primary significance and has, therefore, been investigated extensively. Anneal hardening has also been found in the Al-Cr system where a size misfit of about 5 pct exists, similar to the magnitude of the misfit in the $\mathrm{Cu}-\mathrm{Rh}$ system.

\section{Conclusions}

(I) The alloying element, aluminium, is found to have a pronounced effect on the increase in the recrystallization temperature of copper.
(II) The anneal hardening effect was observed in the $\mathrm{Cu}-$ $\mathrm{Al}$ alloy in the temperature range $180-300^{\circ} \mathrm{C}$, and is accompanied by an increase in electrical conductivity.

(III) The amount of strengthening increases with increasing degree of prior cold work.

(IV) The maximum value of hardness was attained at $70 \%$ deformation.

(V) Anneal hardening may be considered as a genuine hardening mechanism in analogy with the other basic hardening mechanisms such as work, grain size, solid solution and dispersion hardening.

(VI) The results can be applied to derive the composition and processing variables which determine the strengthening effect of copper alloys.

\section{References}

Bader M, Eldis G T and Warlimont H 1976 Metall. Trans. A7 249

Nestorovic S and Markovic D 1999 Mater. Trans. JIM 40222

Nestorovic S and Markovic D 2001 European congress and exhibition on powder metallurgy, Nice, France, Proceedings (UK: EPMA) p. 158

Nestorovic S and Tancic D 2002 International conf. deformation and fracture in structural PM materials, Slovakia, Conf. proc. 2 p. 144

Nestorovic S, Markovic D and Stanojevic B 1997 J. Metall. 4297

Nestorovic S, Milicevic B and Markovic D 2002 Sci. Sinter. 34 169

Vitek J M and Warlimont H 1979 Metall. Trans. A10 1889

Zehtebauer M 1976 Metallkd. 67431 